\title{
Relevance of segmental colitis with diverticulosis (SCAD) to other forms of inflammatory bowel disease
}

\author{
Hugh J Freeman MD FRCPC FACP
}

HJ Freeman. Relevance of segmental colitis with diverticulosis (SCAD) to other forms of inflammatory bowel disease. Can J Gastroenterology 2009;23(6):439-440.

A well localized inflammatory process involving only the sigmoid colonic segment associated with diverticulosis (SCAD), has become increasingly recognized as a distinct clinical and pathological disorder, usually described in older adults, often with rectal bleeding. Although some resolve spontaneously, most patients appear to respond to treatment only with 5-aminosalicylate. Endoscopic evaluation reveals a nonspecific inflammatory process localized in the sigmoid colon that usually completely resolves with histologically normal colonic mucosa. Recurrent symptoms with evidence of recurrent segmental colitis may occur, but most have an entirely benign clinical course. Further definition of the underlying molecular signalling that occurs in this apparently distinctive disorder may be critically important to understand the elements of a colonic inflammatory process that can completely and spontaneously resolve.

Key Words: Colon cancer; Crohn's disease; Diverticulosis; Natural history; Segmental colitis; Ulcerative colitis

Cegmental involvement of the colon with a well circum$\checkmark$ scribed inflammatory process may occur in different forms of infectious colitis or inflammatory bowel disease. In the former, however, disease is more likely to involve multiple different sites within the colon. In ulcerative colitis, the rectum or rectosigmoid segment is involved and the disease usually extends in a continuous pattern proximally within the colonic mucosa for variable distances. During colonoscopic visualization of some patients with ulcerative colitis, this inflammatory process appears to be well demarcated, while in others, less so. In Crohn's disease, any segment of the colon may be involved, most often the cecum and/or the ascending colon. Often, concomitant small intestinal disease is also present. In recent years, other less common, but distinctive forms of inflammatory disease have become better recognized. One segmental form associated with diverticulosis, usually involving only the sigmoid colon, is the so-called 'SCAD syndrome', or more precisely, segmental colitis associated with diverticulosis (1-6).

This form of segmental involvement, especially if it involves only the sigmoid colon, frequently presents with bloody stools. In some, but not all, abdominal pain or diarrhea or both occur. Men are generally affected more often than women and usually most suffer the initial onset of symptoms after the age of 40 or 50 years - somewhat different from the

\section{Importance de la colite segmentaire avec diverticulose vs autres formes de maladie inflammatoire de l'intestin}

Un processus inflammatoire bien localisé n'impliquant que le segment sigmoïde, associé à un syndrome de diverticulose est de plus en plus reconnu comme un trouble clinique et pathologique distinct, habituellement décrit chez les adultes âgés et souvent accompagnés de saignements rectaux. Bien que certains cas rentrent spontanément dans l'ordre, la plupart des patients semblent répondre au traitement par 5-aminosalicylate seulement. L'examen endoscopique révèle une inflammation non spécifique localisée au côlon sigmoïde qui rentre habituellement dans l'ordre complètement avec une muqueuse colique histologiquement normale. Les symptômes récurrents avec signes de colite segmentaire récurrente peuvent survenir, mais la plupart évoluent de façon tout à fait bénigne sur le plan clinique. Une définition plus approfondie des signaux moléculaires sousjacents qui accompagnent ce trouble apparemment distinct serait d'une importance cruciale pour comprendre des éléments d'un processus inflammatoire colique qui rentre complètement et spontanément dans l'ordre.

usual female-predominant distribution of Crohn's disease, including Crohn's disease of the colon. In Crohn's disease, as well, studies have shown that more than $80 \%$ of adults are usually diagnosed well before the age of 40 years (6-8).

As with other forms of idiopathic inflammatory bowel diseases, the cause and pathogenesis of SCAD needs to be better characterized and elucidated $(1,5,9)$. Endoscopic evaluation shows a localized segmental sigmoid inflammatory process with normal rectal and proximal colonic mucosa. Histological studies reveal a nonspecific mucosal inflammatory process localized only in the sigmoid colon $(6,10)$.

In some individuals older than 40 years of age, an earlier diagnosis of a resected colonic neoplasm (ie, adenoma) is not infrequent (6). As a result, a form of selection bias may be present because this subgroup may be simply more aware of the significance of rectal bleeding and their increased risk for recurrent adenomas or colon cancer, thus leading them to seek expedient medical investigation. The good news about the detection of inflammatory mucosal disease is the virtually immediate relief of anxiety that cancer is not present.

Even better news is that most patients diagnosed with this segmental form of colitis, if followed for many years, have been observed to recover, often resolving completely within a few weeks or months with no recurrence (6). Repeat endoscopic

Department of Medicine, Division of Gastroenterology, University of British Columbia Hospital, Vancouver, British Columbia

Correspondence: Dr J Hugh Freeman, University of British Columbia Hospital, 2211 Wesbrook Mall, Vancouver, British Columbia V6T1W5.

Telephone 604-822-7216, fax 604-822-7236, e-mail hugfree@shaw.ca

Received for publication July 11, 2008. Accepted July 12, 2008 
studies, including biopsies, reveal no evidence of residual inflammatory change. Some may have been initially treated with oral 5-aminosalicylates or other symptomatic agents. However, it is not certain whether these medications are necessary because some cases have spontaneously resolved with no traditional pharmacological measures. Occasionally, other medications have been required, including steroids suggesting that there may be a spectrum of disease severity observed over time. In some cases, recurrent discrete episodes were documented and, very rarely, resection of the sigmoid colon was required. To date, no predisposition to the development of benign or malignant colonic neoplastic disease has been documented.

SCAD has special significance. First, and most important, this inflammatory process has a self-limited clinical course that resolves without further recurrence or need for treatment. Because of its similarities to other forms of inflammatory bowel disease, particularly Crohn's colitis, the implications of an inaccurate diagnosis are obvious. A case of segmental colitis

\section{REFERENCES}

1. Sladen GE, Filipe MI. Is segmental colitis a complication of diverticular disease? Dis Colon Rectum 1984;27:513-4.

2. Peppercorn MA. Drug-responsive chronic segmental colitis associated with diverticula: A clinical syndrome in the elderly. Am J Gastroenterol 1992;87:609-12.

3. Gore S, Shepherd NA, Wilkinson SP. Endoscopic crescentic fold disease of the sigmoid colon: The clinical and histopathologic spectrum of a distinctive endoscopic appearance. Int J Colorectal Dis 1992;7:76-81.

4. Imperiali G, Meucci G, Alvisi C, et al. Segmental colitis associated with diverticula: A prospective study. Am J Gastroenterol 2000;95:1014-6.

5. Goldstein NS, Leon-Armin C, Mani A. Crohn's colitis-like changes in sigmoid diverticulitis specimens is usually an idiosyncratic involving the sigmoid colon labelled as Crohn's colitis might lead the treating physician or clinical trial investigator (in the case of new agents) to conclude that a positive outcome was the result of the treatment provided rather than the natural history of an otherwise clinically benign process. Anecdotal accounts of treatment success, including open-label treatment trials of new agents, may be difficult to evaluate, especially if there are claims of 'complete mucosal healing'. Second, the use of modern classification methods used for entities, such as Crohn's disease, that define age of diagnosis, location within the intestinal tract and clinical behaviour may lead to further recognition of other entities so as to permit more precise treatment $(7,8)$. Third, definition of a 'new' or distinct colonic inflammatory process that usually spontaneously resolves raises a critical need to better understand the molecular signalling that may be present, which permits a long-term, benign disease course. More precise treatments for other inflammatory colonic diseases aimed at cure, rather than remission, may then emerge.

inflammatory response to the diverticulosis rather than Crohn's colitis. Am J Surg Pathol 2000;24:668-75.

6. Freeman HJ. Natural history and long-term clinical behavior of segmental colitis associated with diverticulosis (SCAD syndrome). Dig Dis Sci 2008;53:2452-7.

7. Freeman HJ. Application of the Montreal Classification for Crohn's disease to a single clinician database of 1015 patients. Can J Gastroenterol 2007;21:363-6.

8. Freeman HJ. Granuloma positive Crohn's disease. Can J Gastroenterol 2007;21:583-7.

9. Evans JP, Cooper J, Roediger WE. Diverticular colitis - therapeutic and etiological considerations. Colorectal Dis 2002;4:208-12.

10. West $\mathrm{AB}$, Losada M. The pathology of diverticulosis coli. J Clin Gastroenterol 2004;38:S11-S16. 


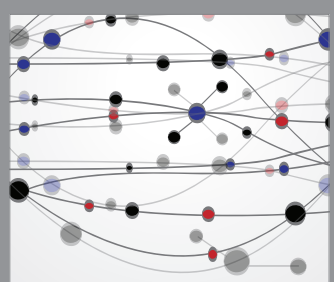

The Scientific World Journal
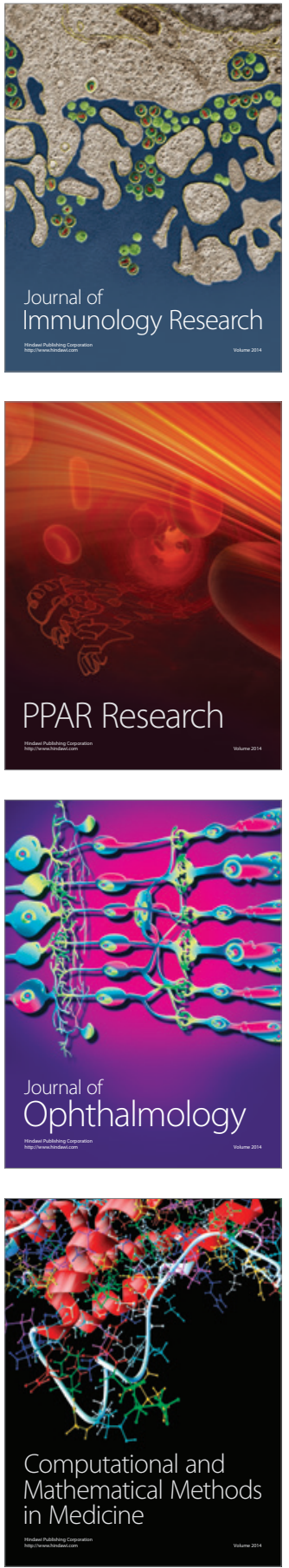

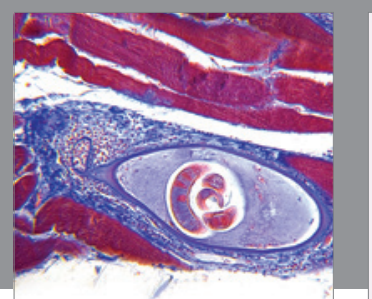

Gastroenterology Research and Practice

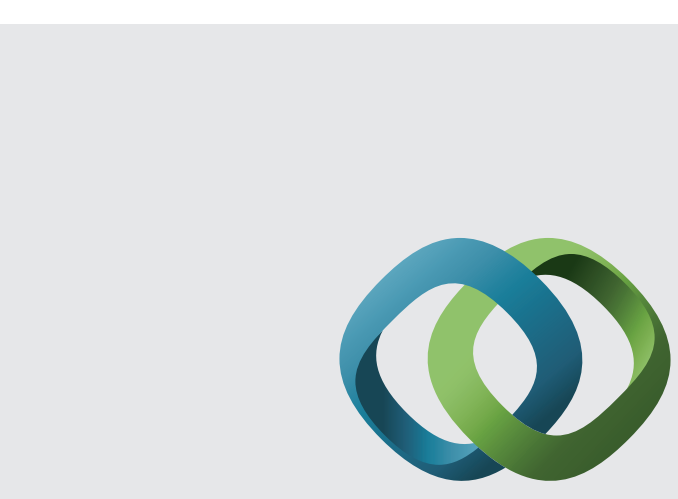

\section{Hindawi}

Submit your manuscripts at

http://www.hindawi.com
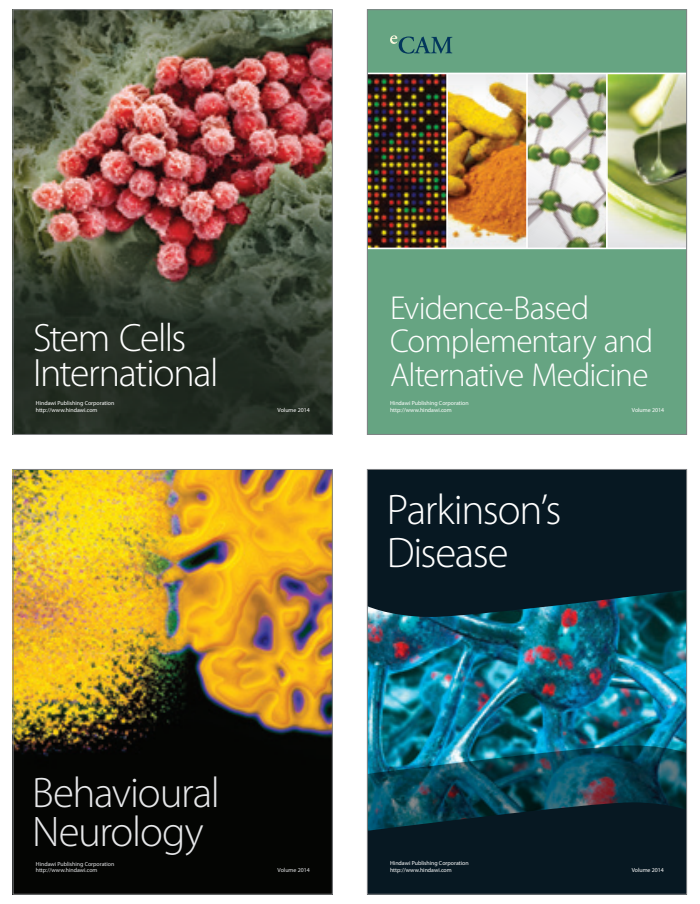
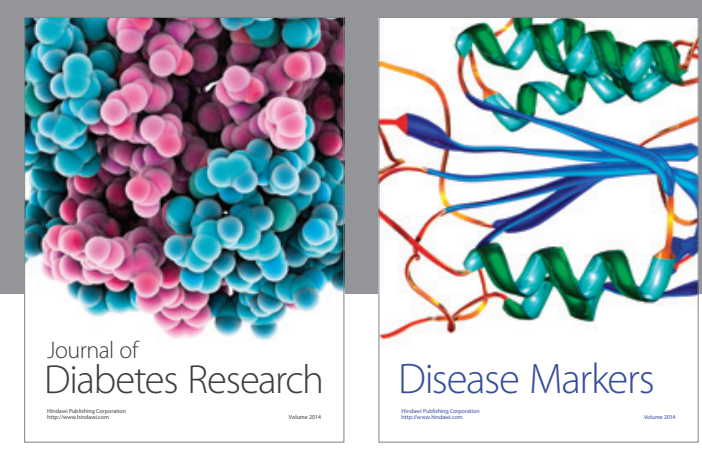

Disease Markers
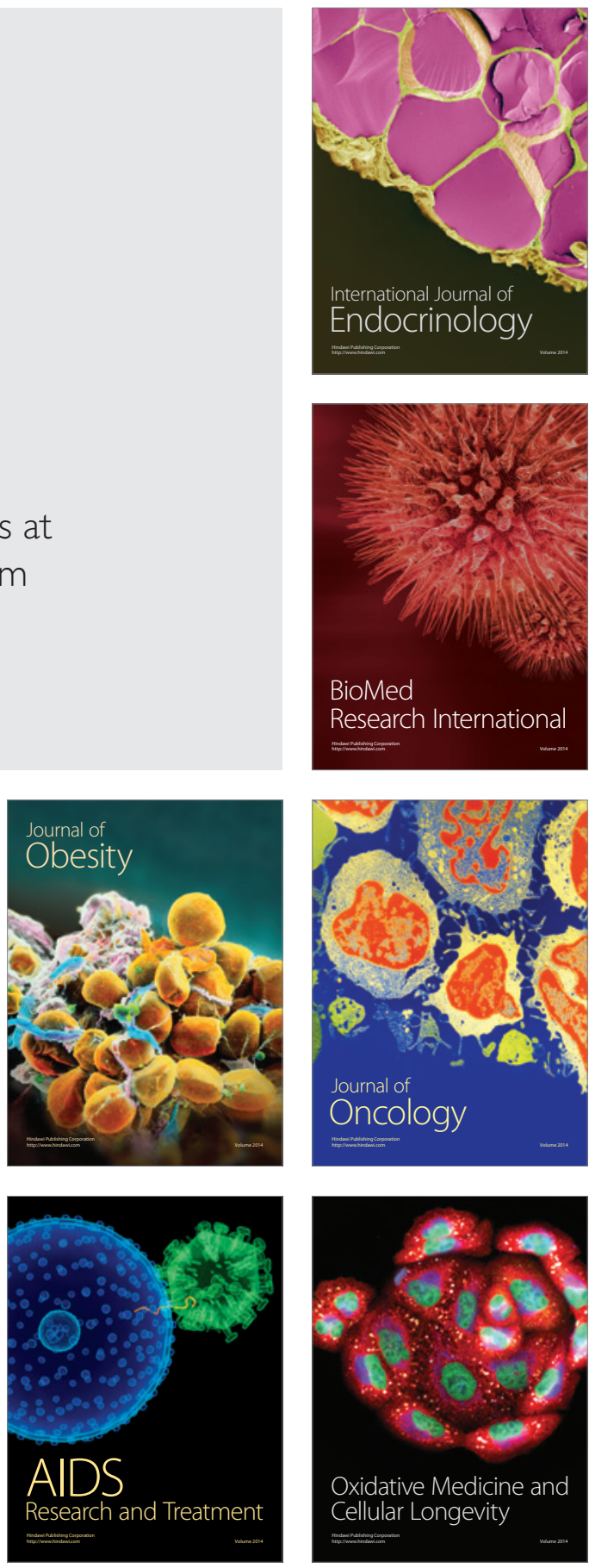